\title{
GEIGER MULLER: A THIN END WINDOW TUBE RADIATION DETECTOR
}

\author{
N.N. Ghuge ${ }^{1}$, Sapna Jasrotia ${ }^{2}$, Anamika ${ }^{3}$, Chilsea Sadhu ${ }^{4}$ \\ ${ }^{1}$ HOD, Electrical Engineering Department, JSPM's BSIOTR, Maharashtra, India, ghuge1974@ gmail.com \\ ${ }^{2}$ B.E. Students, Electrical Engineering Department, JSPM's BSIOTR, Maharashtra, India \\ ${ }^{3}$ B.E. Students, Electrical Engineering Department, JSPM's BSIOTR, Maharashtra, India \\ ${ }^{4}$ B.E. Students, Electrical Engineering Department, JSPM's BSIOTR, Maharashtra, India
}

\begin{abstract}
After various nuclear accidents in different places like Mayapuri locality, Delhi in India (April 2010), San juan de Dios radiotherapy accident in Costa Rica (1996) etc. people are very concerned about their safety and health related issues like cancer, tumor and ultimately death as the radioactivity cannot be noticed by our five senses. To know how much radioactivity is there in a place we need a specific device, like the RADIATION SURVEY METER presented in the paper. It has been designed as economical, easy to use, and accurate for the non-technical public to keep at home or work place and monitors the radioactivity level in the area. This paper represents the use of a gas filled radiation detector, GM tube (Geiger Muller tube), which will sense the radioactivity, sense the gamma radiation, display its intensity and save the data in memory so that it can be further analyzed. The high DC voltages necessary to polarize GM tube (500 - $900 \mathrm{~V})$ can be obtained from batteries or through boost converter with few and less expensive electronic components. The system has been designed using digital display technique using PIC microcontroller, LCD and keys. The system is also facilitated with USB interface.
\end{abstract}

Keywords: Nuclear accidents, radioactivity, radiation survey meter, GM tube

\section{INTRODUCTION}

A nuclear and radiation accident is defined by the International Atomic Energy Agency (IAEA) as "an event that has led to significant consequences to people, the environment or the facility."'Of particular concern in nuclear waste management are two long-lived fission products, Tc99 (half-life 220,000 years) and I-129 (half-life 15.7 million years), which dominate spent fuel radioactivity after a few thousand years. The most troublesome transuranic elements in spent fuel are Np-237 (half-life two million years) and Pu-239 (half-life 24,000 years). Nuclear waste requires sophisticated treatment and management to successfully isolate it from interacting with the biosphere. This usually necessitates treatment, followed by a long-term management strategy involving storage, disposal, or transformation of the waste into a non-toxic form.

The impact of nuclear accidents has been a topic of debate practically since the first nuclear reactors were constructed in 1954. It has also been a key factor in public concern about nuclear facilities. Some technical measures to reduce the risk of accidents or to minimize the amount of radioactivity released to the environment have been adopted. Despite the use of such measures, human error remains, and "there have been many accidents with varying impacts as well near misses and incidents. An attack on or sabotage of a nuclear facility, such as a commercial irradiation facility or a nuclear power plant, could release large amounts of radioactive material.
The Geiger-Muller tube (or G-M tube) is the sensing element of the Geiger counter instrument used for the detection of ionizing radiation. It was named after Hans Geiger, who invented the principle in 1908 and Walther Muller, who collaborated with Geiger in developing the technique further in 1928 to produce a practical tube that could detect a number of different radiation types. Geiger Muller Tube is a portable radiation detection and measurement instrument used to detect presence of radiation in the surrounding. This radiation may be due to alpha particles, beta particles, gamma rays, or $\mathrm{x}$-rays. It also gives us the measure of intensity of radiation.

Our Radiation survey meter is a micro controller based, portable, light weight, battery operated instrument. The Geiger-Mueller counter (GM counter), introduced in 1928, is one of the radiation detectors widely used today. It has simple principle of operation, low cost and its general construction simplicity. It is a gaseous ionization detector and uses the Townsend avalanche phenomenon to produce an easily detectable electronic pulse from as little as a single ionizing event due to a radiation particle. 


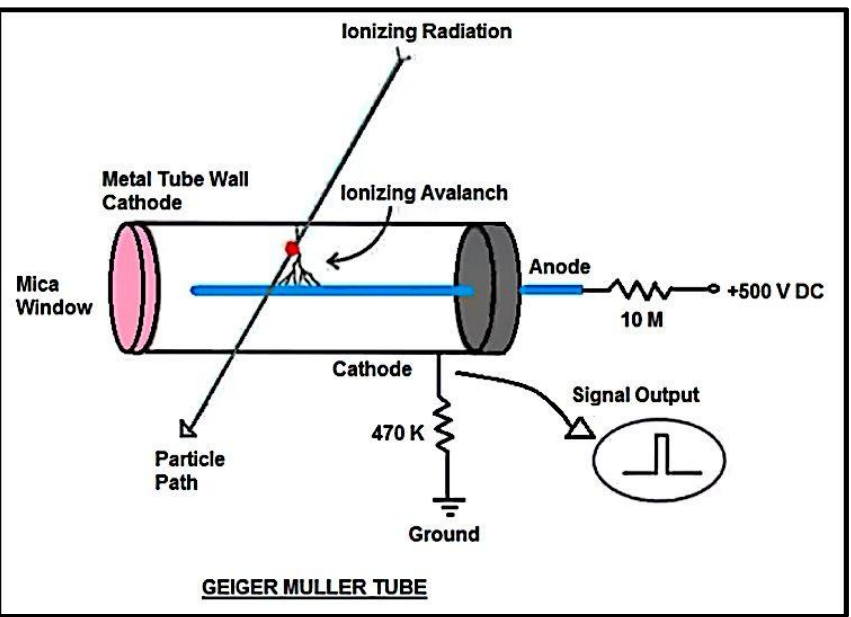

Fig -1: Traditional Geiger Muller counter utilize a thin end window tube and a high voltage supply applied through a resistor

\section{DEVICE CONCEPTS AND OPERATION}

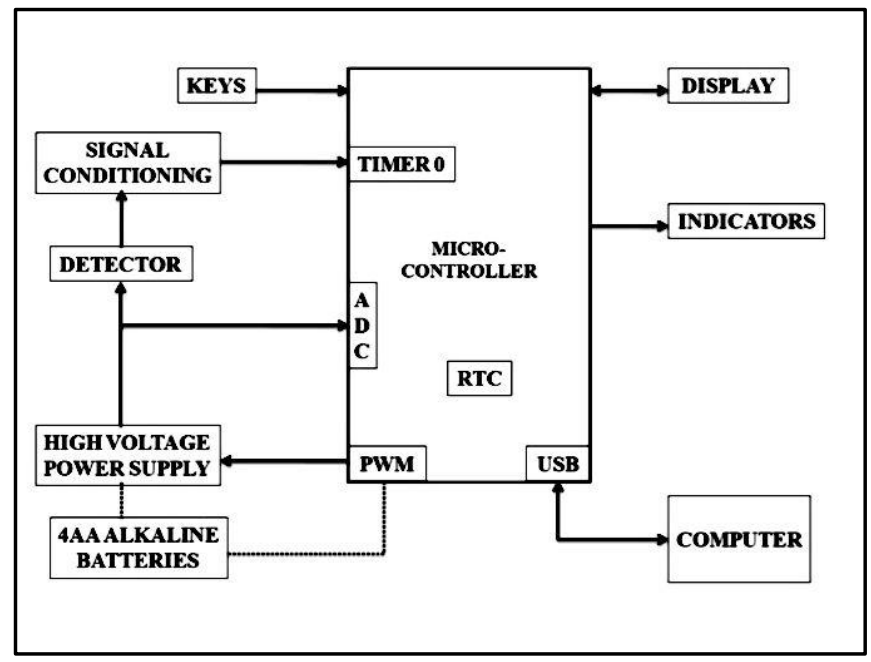

Fig -2: Block diagram of the radiation survey process

\subsection{Detector Circuit}

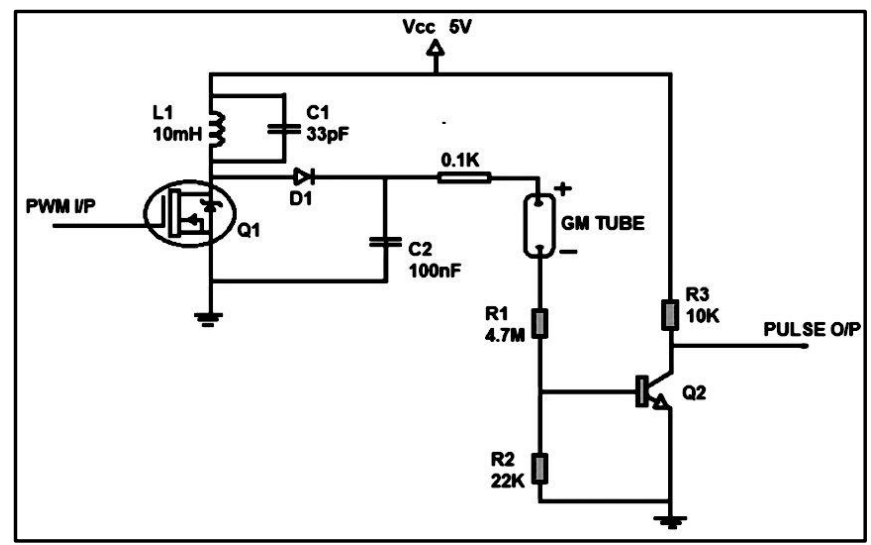

Fig - 3: Detector circuit diagram

Detector circuit consists of the radiation detector (GM tube), a boost converter (to provide necessary voltage required by the GM tube), and a pulse counting circuit (to count and transmit the pulses generated by GM tube.

\subsection{Detector}

We are using GM tube [Type- 131], which is manufactured by Nucleonic Systems, in our project as it is cheaper amongst available tubes with better sensitivity. Also it is smaller in size which reduces the size of the instrument.

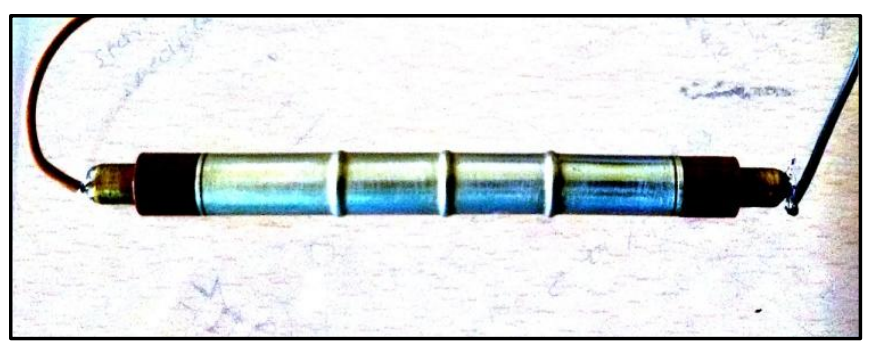

Fig - 4: GM tube STS-5(SBM-20)

\subsubsection{Working of Gm Tube}

Most GM tubes look like metal covered glass cylinders with just two connections. Inside they are filled with a noble gas (Neon is usual, but Helium or Argon can also be used) plus a small amount of a halogen. Electrically, a GM tube is a cylindrical capacitor with the gas as the dielectric. A wire placed along the axis acts as one electrode and the cylindrical metal shield as the other. A large DC voltage (between 500 and $1200 \mathrm{~V}$ ) is set up between the electrodes with no current normally flowing through the gas.

If any ionizing radiation enters the tube and breaks some gas atoms into ions (that is, if it has enough energy) the ions are accelerated by the electrical field and collide with other atoms thus multiplying hugely the number of ions inside the tube. This is known as' avalanche effect'. The result is the dielectric break and an electrical charge flowing through the gas and the electrical circuit the tube is connected to.

\subsubsection{Characteristics}

Figure shows a simplified version of part of the characteristic curve of a Geiger Muller tube; STS-5(SBM20). This characteristic is obtained by plotting the count rate in pulses per second as a function of supply voltage in a constant radiation field. For accurate measurement of radiation intensity tube must be operated in plateau region.

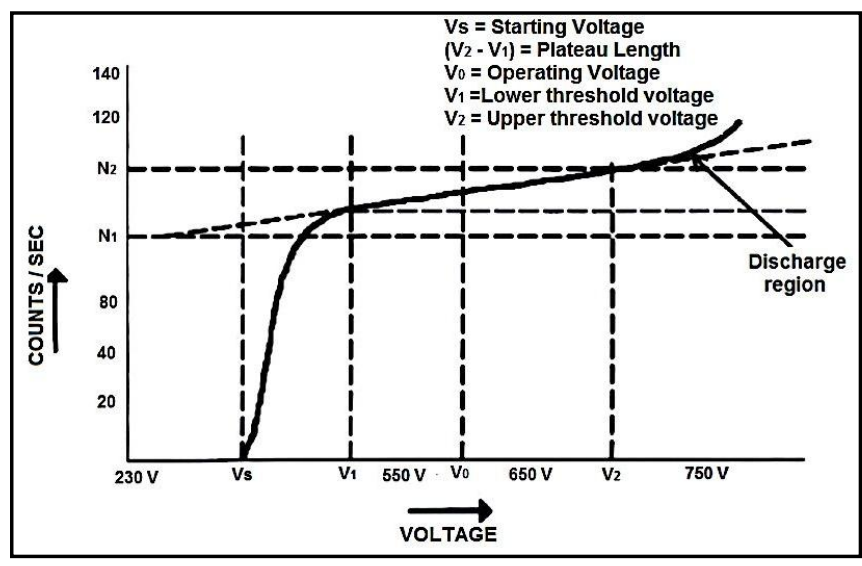

Fig -5: Characteristic curve of GM tube 


\begin{tabular}{|l|l|l|}
\hline 1 & Starting voltage & $280-330 \mathrm{~V}$ \\
\hline 2 & Advised working voltage & $360-440 \mathrm{~V}$ \\
\hline 3 & Plateau length & At least 80V \\
\hline 4 & Plateau slope & $0.125 \% / 1 \mathrm{~V}$ \\
\hline 5 & Maximum natural background & $\begin{array}{l}27 \\
\text { minute }\end{array}$ \\
\hline 6 & Loadses/ \\
\hline 7 & $\begin{array}{l}\text { Allowable stray capacitance of } \\
\text { input circuit }\end{array}$ & $5-10 \mathrm{Mohms}$ \\
\hline 8 & Transit capacitor & $10 \mathrm{pf}$ \\
\hline 9 & Allowable surround temperature & $\begin{array}{l}-40-+50 \text { degree } \\
\text { Celsius }\end{array}$ \\
\hline
\end{tabular}

\subsubsection{Dead Time of Gm Tube}

Dead time is one of the important parameter of GM tube. The dead time is the very brief period following a discharge, during which the Geiger Muller tube is incapable of responding to any subsequent ionizing event. This short period lasts while the effective circuit capacitance is recharged. Normally, most of the residual positive ions are collected by the electric field during this period, but the field is nevertheless too low to allow another discharge, even if further ionizing events occur.

The dead time, DT, is the elapsed time between the beginning of one pulse and the closest next pulse available. The radioactive source must be placed very close to the detector to increase the counts, in this condition, the dead time effect can be noticed more easily. The DT can vary between 20micros and 200micros, depending on the detector model.

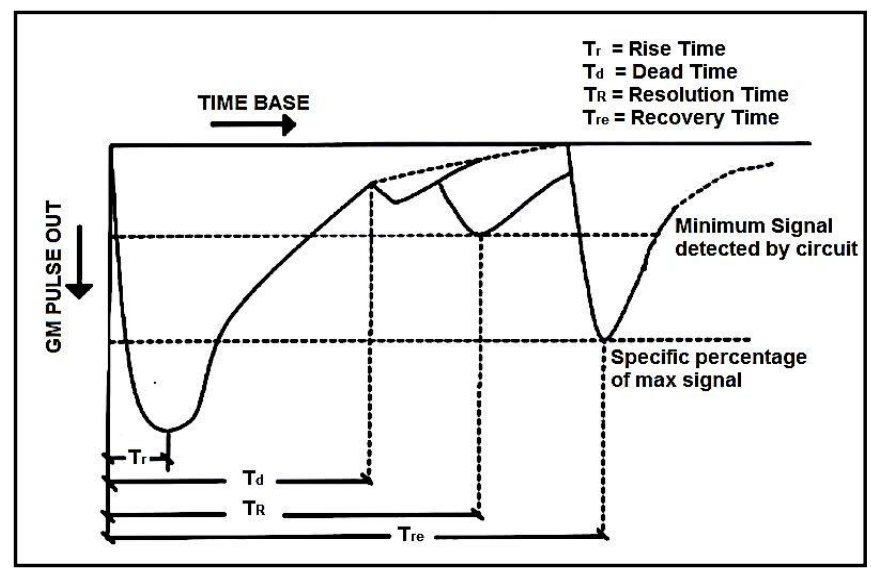

Fig -6: GM detector pulses as seen in the Oscilloscope screen to determine the dead time.

\subsubsection{Dead Time and Count Value}

The dead time after each ionization discharge will limit the maximum count rate because events that occur in the dead period cannot produce a count. The relationship between dead time $\tau$, the true count rate N1 and the measured count rate $\mathrm{N}$ is:

$$
\mathrm{N} 1=\mathrm{N} /(1-\mathrm{N} \tau)
$$

This expression is valid only when $\mathrm{N} \tau \ll 1$.
At high dose rates the probability of an ionizing event occurring within the dead time is high and so a significant number of counts are lost. This effect is usually seen as a non-linearity in the tube characteristic relating dose rate to count rate.

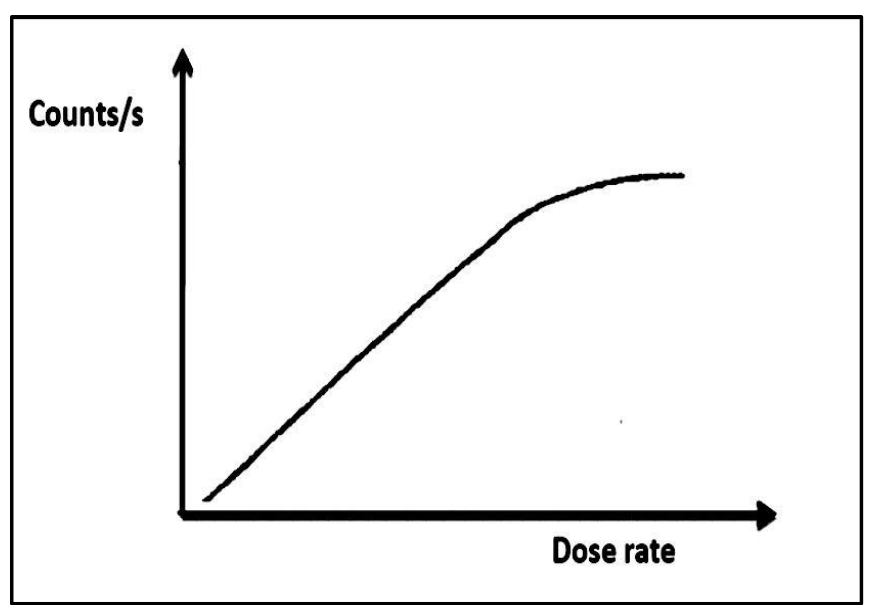

Fig -7: Count Rate versus dose rate for a typical Geiger Muller tube

\subsection{Pulse Counting Circuit}

The output signal at cathode resistor is given to the base of the transistor. The transistor is used as a switch. When base voltage of the transistor is low, transistor is in cut-off mode, so the collector voltage is high. When positive pulse occurs at cathode, base voltage drives the transistor into saturation mode, therefore collector voltage becomes low. The pulses are measured by the controller. Collector terminal of transistor is connected to the pin no. 6 of the PIC controller. Timer0 of PIC controller is used in counter mode to measure pulses. Pin no.6 of PIC microcontroller is external clock input for Timer0. When negative edge appears at pin no.6, Timer0 gets incremented by one.

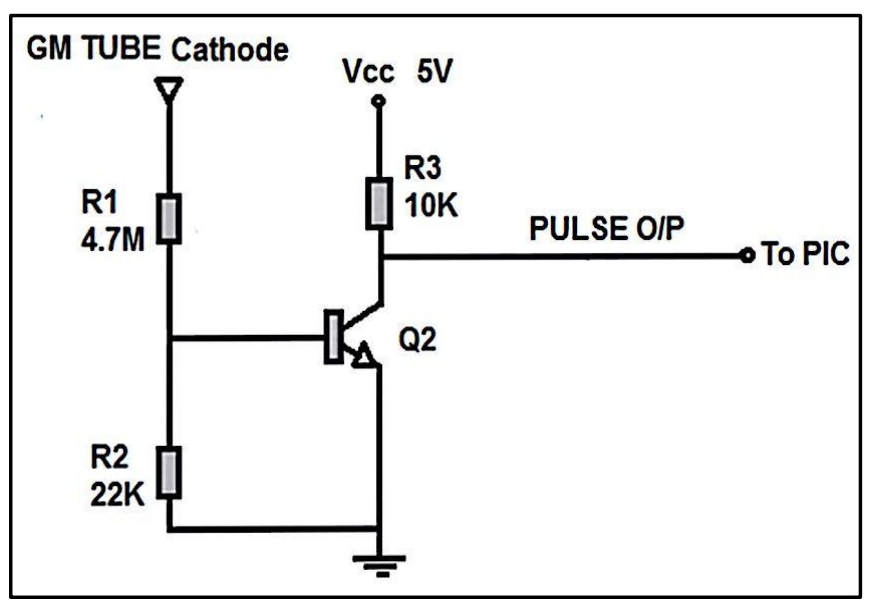

Fig -8: Pulse Counting Circuit

\subsection{Power Supply}

Geiger Muller tube requires high DC voltage (400V $1500 \mathrm{~V}$ ) for its operation. For the tube recommended voltage by manufacturing company is $500 \mathrm{~V}$. Circuitry used for 
generating pulse can be avoided by using PWM feature supported by controller. We have generated $4 \mathrm{kHz}$ signal using PIC controller. For this purpose Timer 1 of PIC is used. The square wave we have generated is used to switch ON and OFF the MOSFET.

The inductor, diode, and capacitor are used as a boost power supply to increase the voltage from $5 \mathrm{~V}$ DC to higher DC voltage.

\subsubsection{Boost Converter}

A boost converter (step-up converter) is a DC-to-DC power converter with an output voltage greater than its input voltage. It is a class of switched-mode power supply (SMPS) containing at least two semiconductors (a diode and a transistor) and at least one energy storage element, a capacitor, inductor, or the two in combination. Filters made of capacitors (sometimes in combination with inductors) are normally added to the output of the converter to reduce output voltage ripple. The switch is typically a MOSFET, IGBT, or BJT.

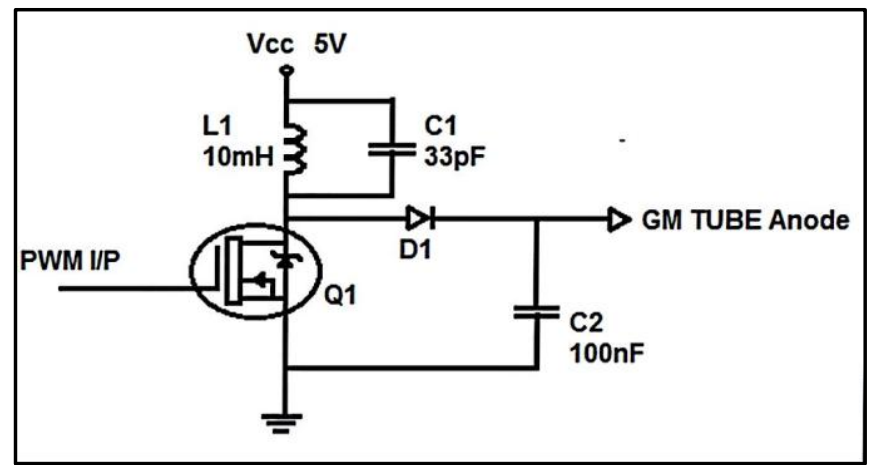

Fig -9: Boost converter circuit

\subsection{Controller}

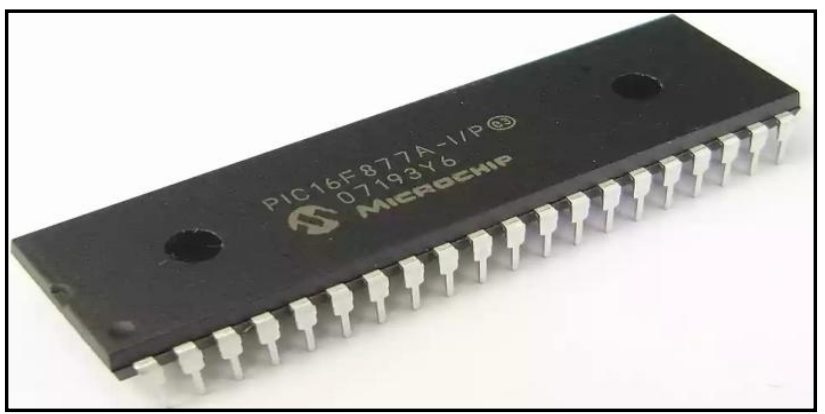

Fig -10: PIC16F877A

We have selected PIC16F877A microcontroller. It is a 40 pin 8-bit CMOS FLASH microcontroller. The core architecture is a high performance RISC CPU; hence, it executes all instructions in single cycle. PIC 16F877A comes with 3 operating speed with 4,8 or $20 \mathrm{MHz}$ clock input. Since each instruction cycle takes 4 operating clock cycles, each instruction takes $0.2 \mu$ s when $20 \mathrm{MHz}$ oscillator is used. It has two types of internal memories; one is program memory and data memory. Programme memory is provided by $8 \mathrm{~K}$ words (or $8 \mathrm{~K}^{*} 14$ bits) of FLASH memory and data memory has two sources. One type of data memory is a 368 byte RAM and the other is 256 byte EEPROM. The core feature includes interrupt upto 14 sources, power saving SLEEP mode, a single 5V supply, and In-Circuit Serial Programming (ICSP) capability. The sink/source current, which indicates a driving power from $\mathrm{I} / \mathrm{O}$ port, is high with $25 \mathrm{~mA}$. Power consumption is less that $2 \mathrm{~mA}$ in $5 \mathrm{~V}$ operating condition.

\subsection{Display Module}

We have used 16X2 LCD (JHD162A) in the 'Radiation Survey Meter' for its following features:-

1. Wide viewing angle and high contrast

2. 5-7 dot character matrix with cursor

3. Interfaces with 4- bit or 8- bit MPUs

4. Display upto 226 character and special symbols

5. Custom character patterns are displayed with the character RAM

6. Abundant instruction set including clear display, cursor on/off, and character blinking.

7. Compact and light weight for easy assembly to the host instrument

8. Operable on single $5 \mathrm{~V}$ power supply

9. Low power consumption

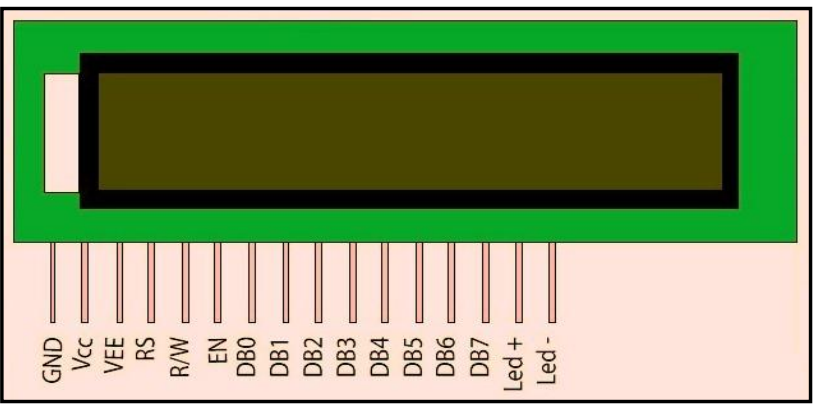

Fig -11: LCD 16X2 display

\subsection{RS-232 using MAX 232}

In telecommunications, RS-232 is a standard for serial communication transmission of data. It formally defines the signals connecting between a DTE (data terminal equipment) such as a computer terminal, and a DCE (data circuit-terminating equipment, originally defined as data communication equipment, such as a modem. The standard defines the electrical characteristics and timing of signals, the meaning of signals, and the physical size and pin out of connectors. The current version of the standard is TIA-232F Interface between Data Terminal Equipment and Data Circuit-Terminating Equipment Employing Serial Binary Data Interchange, issued in 1997.

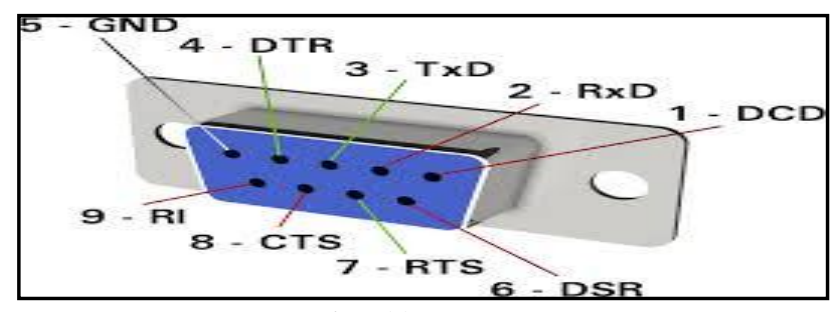

Fig -12: RS-232 
MAX232 is an IC that converts signal from an RS232 serial port to signals suitable for use in TTL compatible digital logic circuits. The MAX232 is a dual driver/receiver and typically converts the Rx, Tx, CTS and RTS signals. The driver provides RS 232 voltage level output (approx $\pm 7.5 \mathrm{~V}$ ) from a signal $+5 \mathrm{~V}$ supply via on-chip charge pumps and external capacitors. This makes it useful for implementing RS 232 in devices that otherwise do not need any voltage outside $0 \mathrm{~V}$ to $+5 \mathrm{~V}$ range, as power supply design does not need to be made more complicated just for driving RS 232 in this case. The receiver reduces RS232 inputs (which may be as high as $\pm 25 \mathrm{~V}$ ), to standard $5 \mathrm{~V}$ TTL levels. These receivers have a typical threshold of $1.3 \mathrm{~V}$, and a typical hysteresis of $0.5 \mathrm{~V}$

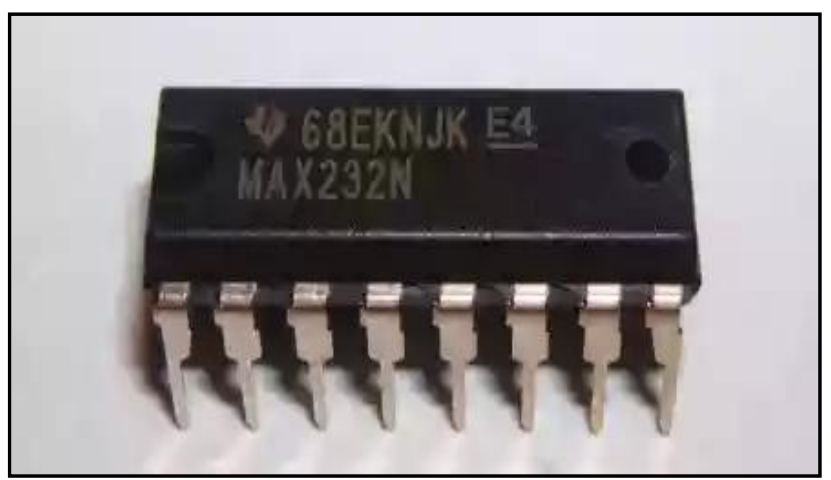

Fig -13: MAX232 IC

\subsection{Alarm Indicator}

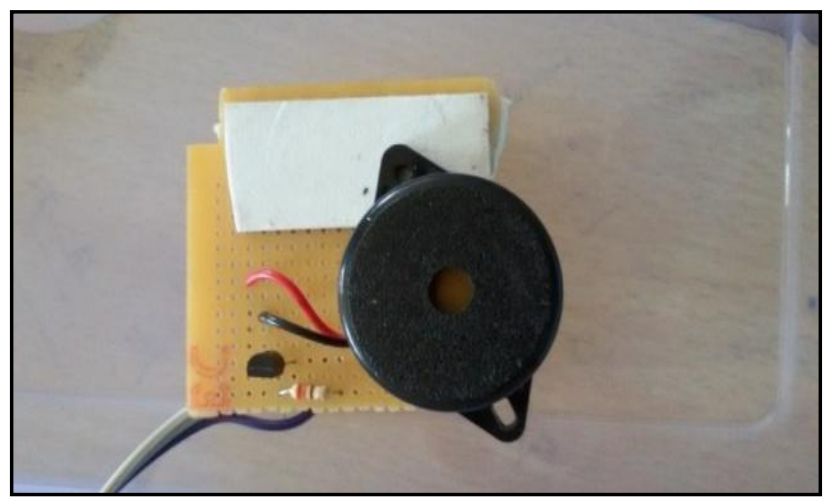

Fig -14: Alarm indicator

Alarm indicator used in the project is to give a sound for every increase in pulse count by 10 within 10 seconds. Buzzer circuit consists of an n-channel transistor and a resistor of $330 \Omega$. When the radiation reading value will succeed the predefined safe limit value of radiation, the microcontroller will give signal to the buzzer circuit, and an audible alarm sound will be heard. The alarm circuit is provided to indicate that the radiation level in the environment has increased beyond the safe value.

\section{DEVICE CHARACTERISTICS}

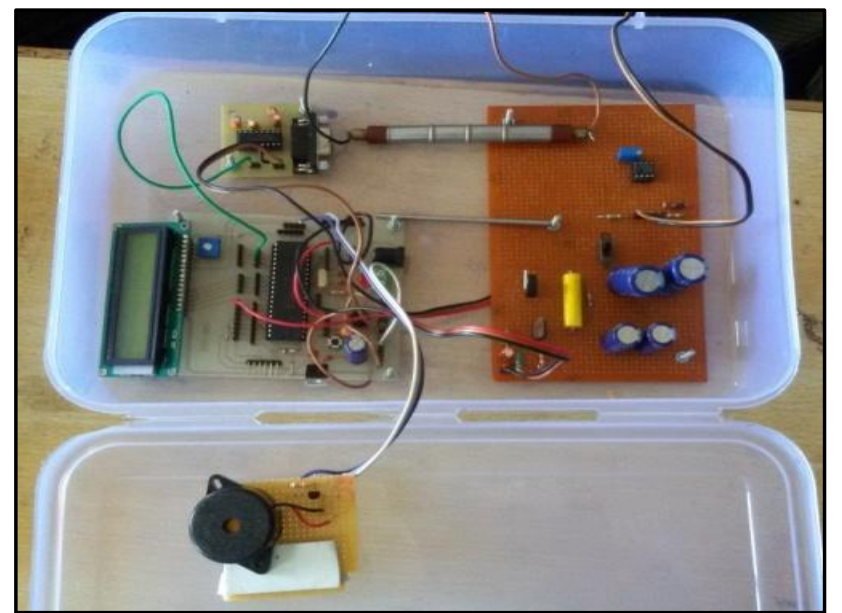

Fig -15: Hardware of the radiation survey process

1. The 500V DC GM tube biasing voltage is generated by a PIC microcontroller in boost power supply configuration.

2. The display is menu driven with LCD digital readout.

3. Microcontroller 'sleep' mode is used to reduce power consumption

4. Radiation measurements are date/time stamped by an internal real time clock.

5. Internal memory can store 375 radiation measurements using PIC16F877A.

6. Built-in USB interface for data upload to a personal computer.

7. PIC firmware is written in freely available $\mathrm{C}$ language.

\section{OBSERVATIONS}

We have observed and noted down the readings obtained using the radiation source Thorium of Symbol Th and atomic number 90 . It is a radioactive actinide metal. The half life of thorium-232 is about 14 billion years.

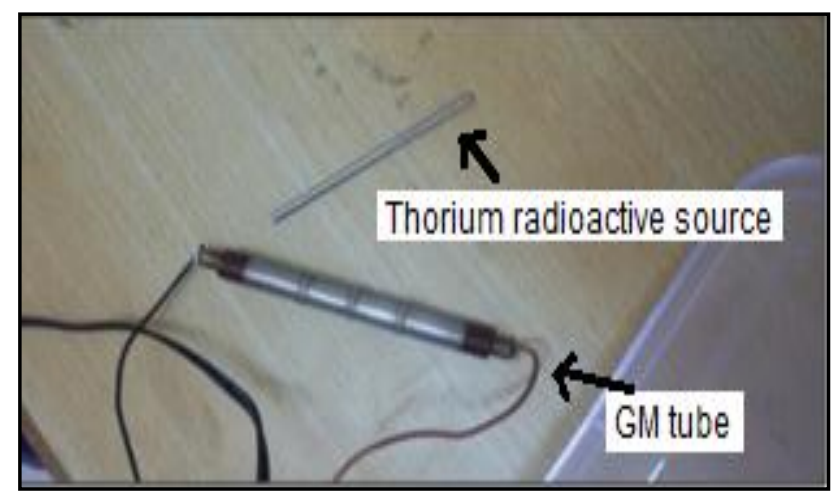

Fig -16: Thorium rods-radioactive source

The readings on GM tube are obtained under three situations:

1. When there is no radioactive source around

-In this case the GM tube must show background noise reading (which is predefined as $\leq 10$ pulses per 10 seconds)

2. When the Radioactive source is kept around the GM tube (distance up to $15 \mathrm{~cm}$ ) 
- In this case the reading must be $\geq 10$ pulses per 10 seconds and the buzzer must start sounding.

3. When the radioactive source is kept on the GM tube (by placing paper between tube and source to avoid direct contact between them)

- In this case the reading must be higher and the buzzer must sound

The Observation Table below shows the readings obtained.

\section{Observation Table:}

Following readings are taken for counts per10 seconds.

Table -1: Readings observed

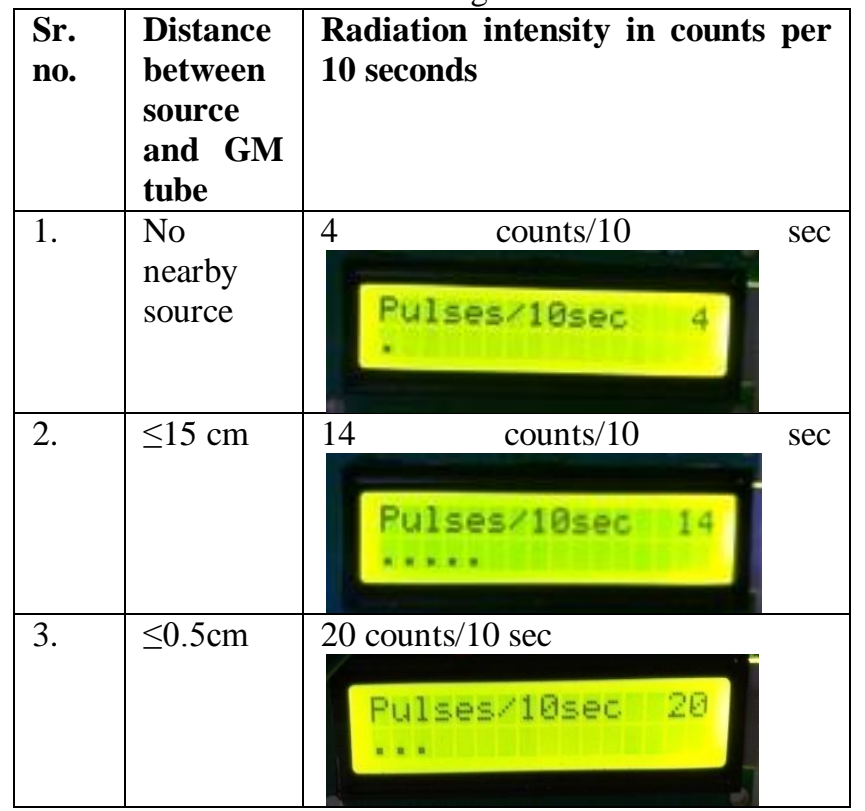

\section{RESULTS}

Sensitivity of STS -5/SBM-20 GM tube for Cobalt- 17 $\mathrm{cps} / \mathrm{mR} / \mathrm{hr}$

$1 \mathrm{cps}=0.06 \mathrm{mrem} / \mathrm{hr}$

- Conversion formula:

Sensitivity $=\frac{\text { counts per second }}{\frac{\mathrm{mrem}}{\mathrm{hr}}}$

Table -2: Results calculated

\begin{tabular}{|l|l|l|l|}
\hline $\begin{array}{l}\text { Sr } \\
\text { No. }\end{array}$ & $\begin{array}{l}\text { Distances } \\
\text { between } \\
\text { source } \\
\text { and GM } \\
\text { tube }\end{array}$ & $\begin{array}{l}\text { Radiation } \\
\text { intensity } \\
\text { Counts per 10 } \\
\text { seconds }\end{array}$ & $\begin{array}{l}\text { Radiation level in } \\
\text { standard unit; } \\
\text { mrem/ hr }\end{array}$ \\
\hline 1. & $\begin{array}{l}\text { No } \\
\text { source } \\
\text { nearby }\end{array}$ & $\begin{array}{l}4 \text { counts per 10 } \\
\text { sec }\end{array}$ & 0.0235 \\
\hline 2. & $\leq 15 \mathrm{~cm}$ & $\begin{array}{l}14 \text { counts per 10 } \\
\text { sec }\end{array}$ & 0.0823 \\
\hline 3. & $\leq 0.5 \mathrm{~cm}$ & $\begin{array}{l}20 \text { counts per } 10 \\
\text { sec }\end{array}$ & 0.1176 \\
\hline
\end{tabular}

\section{Graphs on Terminal Software}

The below figure shows the graph obtained on TERMINAL Software for the reading obtained.

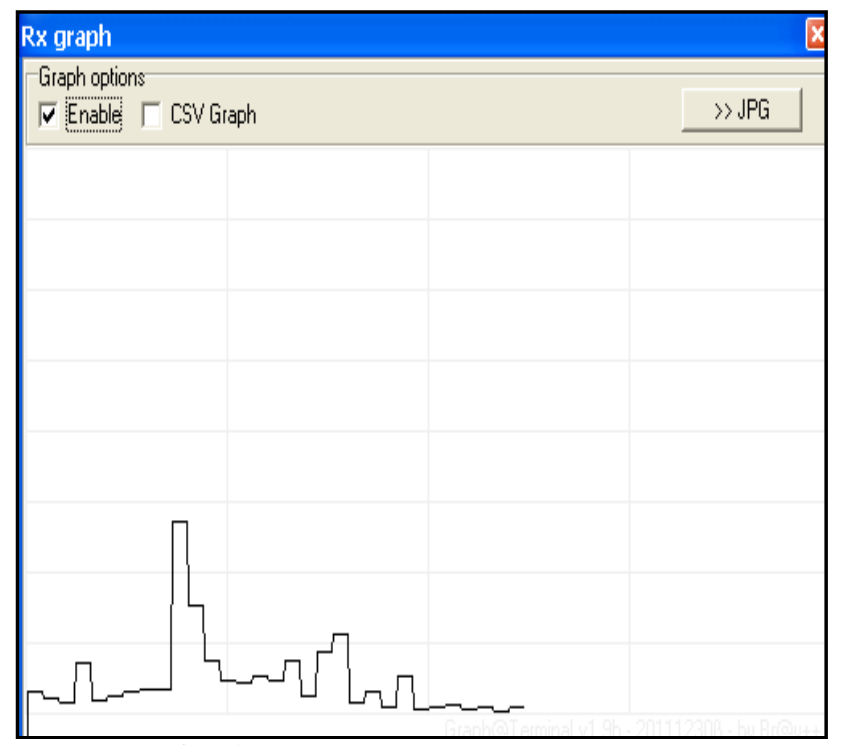

Fig -17: Graph on Terminal Software

\section{Data Stored in Docklight Software}

The figure below shows the data stored in the DOCKLIGHT software for the readings obtained.

\begin{tabular}{|l|l|l|l|l|}
\hline ASCll| & HEX Decimal $\mid$ Binary \\
\hline 20/3/2015 12:14:10 - 00030201040604020304040505091820242023191805040712 \\
000100
\end{tabular}

Fig -18: Reading stored in Docklight software

\section{CONCLUSION}

Radiation detectors are widely used in industrial applications (nuclear power plants and military applications) as well as in research surveys for detecting emission of radioactive radiations. This project discusses the implementation where a large sized, complicated detector is replaced by compact GM tube radiation detector, in order to prepare a small sized, mobile and inexpensive radiation detection device based on low cost PIC microcontroller. These controllers help in detecting the radiations emitted by radioactive material with minimum external hardware requirement by retaining the efficiency of detector and hence reducing the cost of detection device making it more affordable.

\section{REFERENCES}

[1]. H. Geiger and W. Muller," Geiger Counter Tube, "Naval Research Laboratory, 25th May 1949.

[2]. Chester G. Wilson and Yogesh B. Gianchandani, "Microgeiger: A Microfabricated Gas Based Beta Radiation Detector," Solid State Sensor, actuator and Microsystem workshop Hilton Head Island, South Carolina, June 6-10, 2004.

[3]. Rania Gomaa, IhabAdly, Karan Sharshar, Ahmed Saiwat, Hani Ragai, "Zigbee Wireless Sensor Network For Radiation Monitoring At Nuclear Facilities,” IEEE 2013. 
[4]. Koviljka Stankovic and Predrag Osmokrovic, "The Model For Calculating The Type A Measurement Uncertainty Of GM Counter From The Aspect Of Device Miniturization," IEEE $3^{\text {rd }}$ June 2014.

[5]. Jerrold T. Bushberg, Linda A. Kroger, Marcia B. Hartman, Edwin M. Leidholdt ,Jr,Kenneth L. Miller, Robert Derlet, and Cheryl Wraa,"Nuclear/Radiological Terrorism: Emergency Department Management Of Radiation Casualties," ELSEVIER 2007. 